\title{
Electricity Generation through Train Forward Motion to Reduce Power Consumption in Train's Auxiliary System
}

\author{
Jean d'amour Nizeyimana
}

\begin{abstract}
Rail transport around the world is developing very fast. There is no doubt that in the future it will be one of the most used transportation means. Different forms of railway transport have been used since its birth such as steam locomotives, Diesel electric locomotive, electric locomotives and Magnetic levitation (MAGLEV) trains. This paper aims at reducing power consumption in auxiliary system of Electric locomotives which use electrical power as a prime mover by producing electricity through train motion. Simulation in Matlab is done whereby a permanent magnet DC motor is attached to train wheel axle and with the relative motion of the rotor in the magnetic field of the permanent magnet stator produced by rotation of axles generate electricity which is stored in batteries and then supplied to auxiliary system of the train. The simulation of the system demonstrated that electricity produced is enough to power the auxiliary system, hence reducing power consumption by the train.
\end{abstract}

Index Terms - Rotor; Magnetic field; Auxiliary system; Electric train.

\section{INTRODUCTION}

Electrical energy is something expensive to generate around the world especially in Africa. Hence, its efficient use is required. In electrical railway systems, the train moves by electrical energy from the supply line whether overhead line or third rail. This power is used to feed the electrical traction motors for train's forward motion and the rest is used to power auxiliary systems such as lighting, ventilation, door opening, train control and communication system and so on. The power spent in the auxiliary system accounts almost $30 \%$ of the total consumed power. However, it can be reduced and the saved amount of it can be used in other energy requirement systems outside of the train such as lighting offices, ticket selling machines ...etc.

In this paper, a system is designed to generate electricity which is then used to power auxiliary system. The working principle is based on a changing magnetic field which induces voltage in a nearby conductor, if the conductor is connected with a resistance, an induced current flows through it.

Energy has many forms such as chemical energy, potential energy, electrical energy, mechanical energy and so on. Electrical energy can be obtained from conversion of other energy forms into electrical form. K. Jäger, O. Isabella [1] in their research showed that electric energy consumption around the world is about $17 \%$ of the total energy consumed world widely. However, for electrical energy production, most of it is achieved through converting chemical energy into electrical energy, a process in which chemical energy is converted into thermal energy, the produced thermal energy converted into mechanical energy and then converting the mechanical energy into electrical energy.

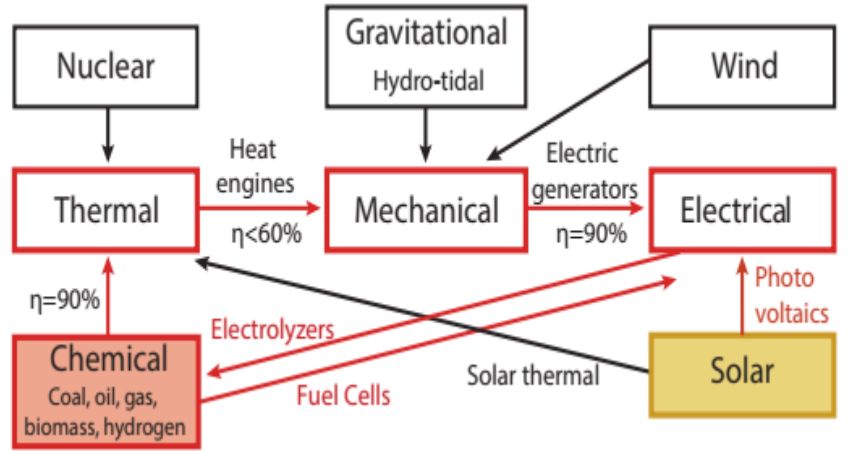

Fig 1: Electrical energy generation process [1]

This conversion process is around $48.6 \%$ efficient for electrical energy output due to conversion system inefficiencies and the rest of it which is around $51.4 \%$ is lost in the conversion system as shown in Figure 1. Other conversion forms are gravitational energy which is converted into mechanical energy and then converted into electrical energy; solar energy converted directly into electrical energy or into thermal before converting it back to electrical energy and Nuclear energy which goes through a conversion process to give electrical energy.
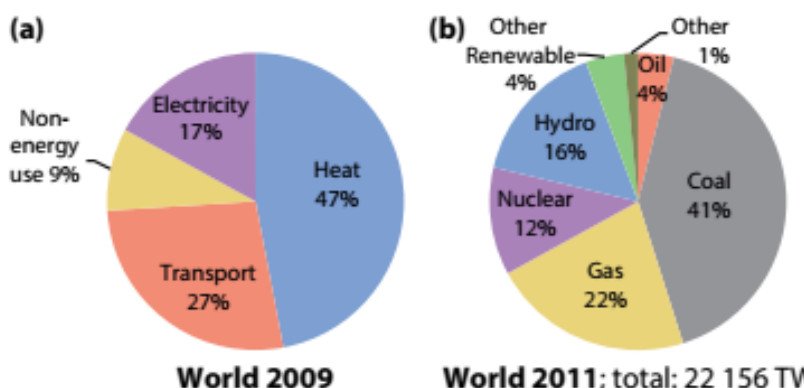

World 2011; total: 22156 TWh

Fig 2: (a) The final energy consumption by energy service and (b) the energy carriers used for electricity generation[1]

It can clearly be seen from figure 2 that energy carriers used for electricity generation, $67 \%$ of them are from fossil fuels which are depleted faster than their production process and are not environment friendly. Due to complexity of energy conversion system, the price of electric energy is high and its efficient use is of paramount importance including its use in electrical railways.

\section{SYSTEM MODELLING}

Energy can be defined as the capacity of a physical system to do work. We can recall that energy is never created nor can it 
be destroyed. However, the form of energy can change from one form into another form but its total amount cannot be changed. We can convert electrical energy into mechanical energy as well as changing mechanical energy into electrical energy.

\section{A. Principle of Electric Energy Generation}

According to Faraday's laws of electromagnetic induction, whenever a conductor is placed in a varying magnetic field (or a conductor is moved in a magnetic field), an EMF (electromotive force) gets induced in the conductor. If a closed path is formed by connecting a resistance across the conductor, an induced current flows in it. The induced EMF can be calculated from the below equation:

$$
\mathrm{EMF}=\mathrm{NBLVSin} \varnothing
$$

Where B is the magnetic flux density, L the length of one coil, $\mathrm{V}$ the speed of the conductor, $\varnothing$ the angle between the wire and the magnetic flux and $\mathrm{N}$ is the number of coils.

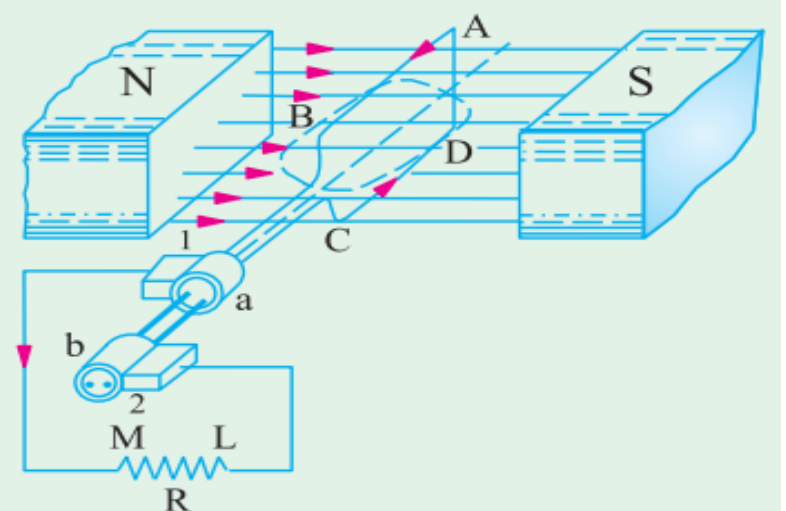

Fig 3: Induced emf by rotating a wire in a magnetic field [2]

This principle of generation is the one used in electric generators among which a permanent magnet DC generator has been chosen in this paper due to its different advantages such as being relatively smaller in size, no need of field excitation winding, hence construction is simpler, no need of electrical supply for field excitation, hence PMDC generators are relatively more efficient and they are cheap in construction cost[3].

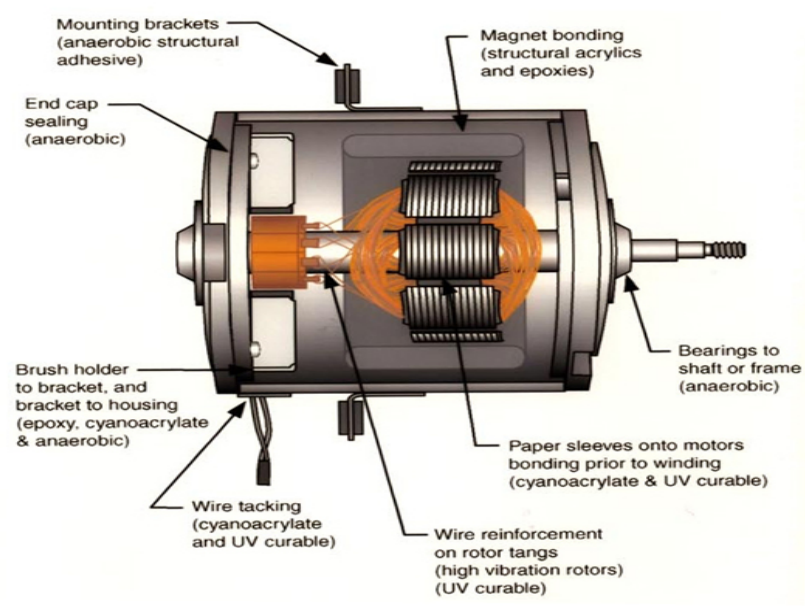

Fig 4: Typical permanent DC Generator assembly[4]

\section{A. System Design and Simulation}

In order to produce induced EMF it is necessary to produce rotating magnetic field in coils or rotating the coils in a magnetic field. The copper windings which form the armature or rotor of generator are connected on train's bogie axles. As traction motors rotate the axles of the bogie to rotate wheels for motion, the coils rotate with the axles and these coils rotate in a magnetic field of a permanent magnet DC generator stator. Then, an EMF is generated due to rotating motion of the coils. A permanent magnet DC generator (PMDC) has been designed using Halbach arrays as the stator for a focused magnetic field towards the rotor windings.

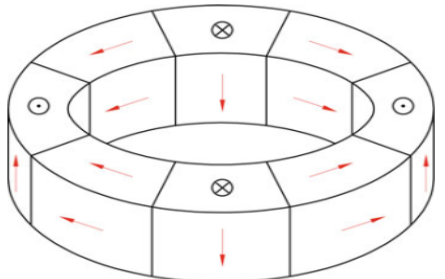

Fig 5: Halbach array for the permanent magnet DC generator[5]

This principle is applied to produce electricity from the train forward motion. Batteries carried on board of the train are used to store this generated electricity which has to be used in auxiliary systems, lighting system for the case being.

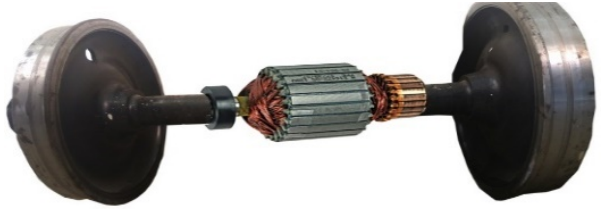

Fig 6: Rotor attached to wheel axle

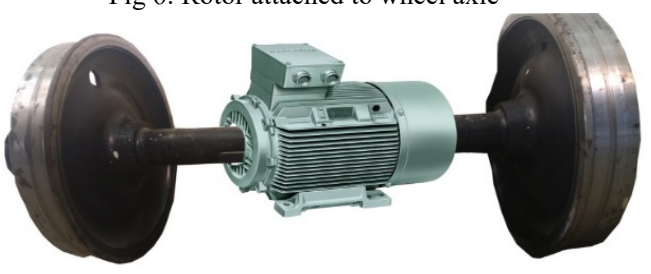

Fig 7: Axle-PMDC generator assembly

This Permanent Magnet generator lies on the bogie system of the train with its armature rotating with the axle rotation by traction motors hence generating electricity. This electricity is fed to the auxiliary system of the train

\section{SYSTEM SIMULATION AND CONTROL IN MATLAB SIMULINK TOOL}

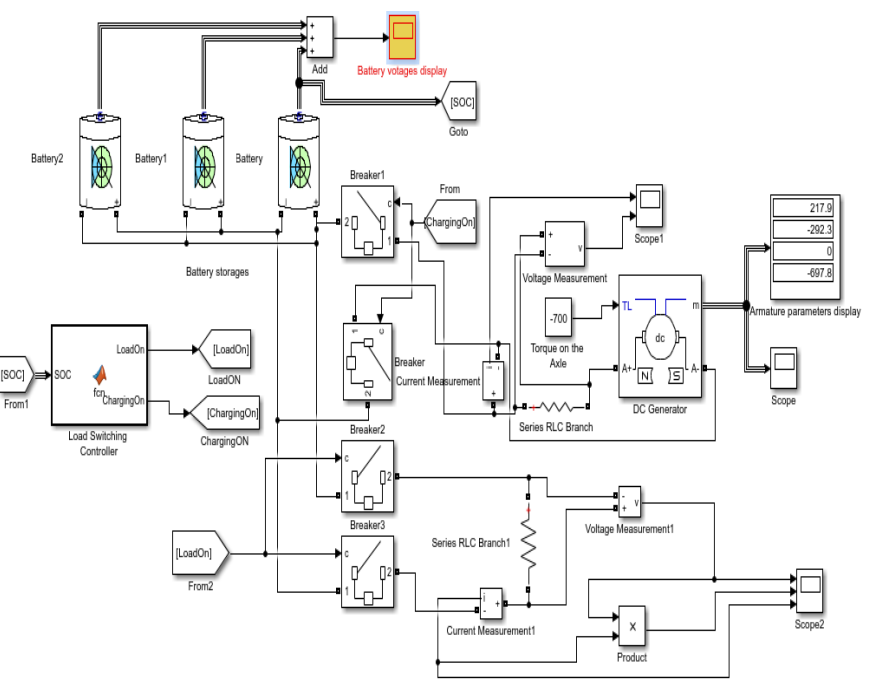

Fig 8: Simulation of the DC Generator using Simulink 
The designed system has Four (4) major important parts: The permanent magnet DC generator, Battery storage, Load switching controller and Circuit breaker system.

\section{A. Permanent magnet generator}

The permanent magnet DC generator is the heart of the system generating voltage output of $300 \mathrm{~V}$ minimum to feed the auxiliary system with power. It has for input the torque generated by traction motors of the train which in this case a -700 torque is used and this gives the desired output voltage to run as a generator and not motor in Matlab Simulink software.

The input torque to the PMDC is generated by traction motors and can be found using the following formula:

$T_{g}=k \frac{s E_{1}^{2} R_{2}}{R_{2}^{2}+\left(s X_{2}\right)^{2}}$

Where $\mathrm{k}$ is the constant of the given motor, $\mathrm{s}$ is the slip, $\mathrm{E}_{1}$ is the input voltage of the motor, $\mathrm{R}_{2}$ is the winding resistance and $\mathrm{X}_{2}$ is winding inductance.

The voltage output of the generator can be derived from the equation: $V_{T=} E_{A}-I_{A}\left(R_{A}+R_{S}\right)=K \emptyset \mathrm{W}-\sqrt{\frac{T}{K C}}\left(R_{A}+R_{S}\right)$

(3)

Where VT is the output voltage of the generator, $\varnothing$ is the flux density, $\mathrm{G}$ is the angular velocity, $\mathrm{T}$ is the torque applied, $\mathrm{Rs}$ $=0$ since we have no stator winding, $\mathrm{Ra}$ is the armature resistance, $\mathrm{K}$ and $\mathrm{Kc}$ are generator constants.

\section{B. Battery storages system}

The generated electrical energy is necessary to be stored for reuse. For this, battery cells are grouped together into a single mechanical and electrical unit called a battery module. These modules are electrically connected to form a battery pack, which powers the electronic drive systems. For this system, Lithium -Ion battery is chosen for storing electricity due its following advantages:

- High energy density: These batteries have much greater energy density which is one of the chief advantages of a lithium ion battery or cell. The much higher power density offered by lithium ion batteries is a distinct advantage [6]-[7].

- Self-discharge: One issue with batteries and cells is that they lose their charge over time. This selfdischarge can be a major issue. One advantage of lithium ion cells is that their rate of self-discharge is much lower than that of other rechargeable cells such as Ni-Cad and NiMH forms [6] .

- No requirement for priming: Some rechargeable cells need to be primed when they receive their first charge. There is no requirement for this with lithium ion cells and batteries [6]- [7].

- Low maintenance: One major lithium ion battery advantage is that they do not require any maintenance to ensure their performance. Ni-Cad cells required a periodic discharge to ensure that they did not exhibit the memory effect. As this does not affect lithium ion cells, this process or other similar maintenance procedures are not required [6], [7].
- Variety of types available: There are several types of lithium ion cell available. This advantage of lithium ion batteries can mean that the right technology can be used for the particular application needed. Some forms of lithium ion battery provide a high current density and are ideal for consumer mobile electronic equipment. Others are able to provide much higher current levels and are ideal for power tools and electric vehicles.

- In addition to their potential for high-specific energy, Li-ion batteries also have an outstanding potential for long life. Under normal operation, there are few structural changes of the anodes and cathodes by the intercalation and removal of the smaller lithium ions [6], [7].
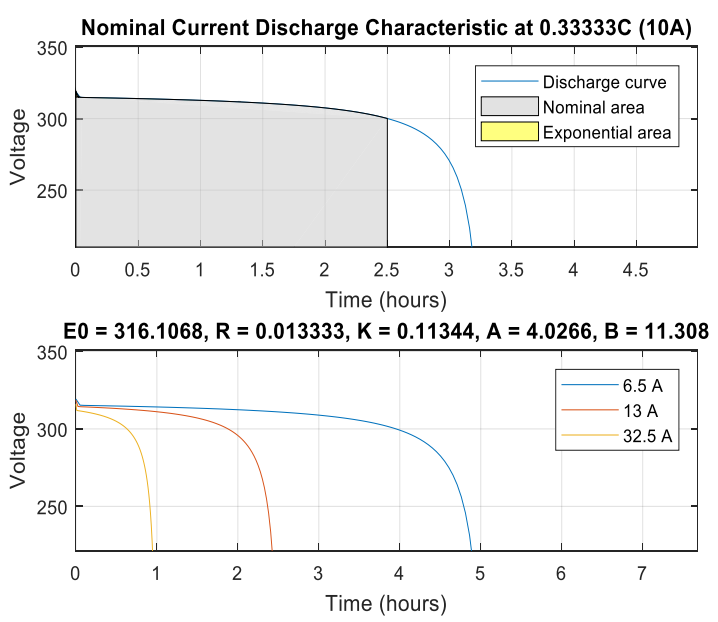

Fig 9: Discharge characteristics

The above graphs of Figure 9 show that the stored energy in batteries once fully charged can last for at least 2.5 hours before any charging takes place once discharging at $10 \mathrm{~A}$ which is nominal current required for lighting systems. However, this battery can last up to 4 hours before charging if feeding train lamps at 6.5 amperes which is the case when using LED lights.

\section{Circuit Breakers}

Circuit breaker is an automatic device used for stopping the flow of current in electric circuit as a safety measure. In the third part of this project simulation diagram we have 4 circuit breakers, 2 are working at the same time on side of batteries and other 2 circuit breaker are working at the same time on side of load. Batteries are charged by the current from electric dc generator. If batteries are fully charged, circuit breaker 1 , 2 will cut off the circuit to batteries and start to discharge trough the load, there is no current flow from generator because we have an open circuit. Batteries are discharged through circuit breaker 3 , and 4 . If batteries are discharged up to $40 \%$ circuit breaker 1, 2 will close again to charge batteries. While batteries are charging a part of power from generator will be supplied to the load so that the load will not lose power until battery are charged again to the nominal level (80\%) when circuit breaker 1, 2 will be open.

\section{Charge Control Circuit}

The action of the charge control circuit is control over the circuit breakers. It determines when to charge the batteries, meaning when they get to $40 \%$ discharge and switch on the circuit breakers for charging and opens them to discharge 
batteries through load circuit when they get charged to their nominal level.

\section{EFFECT OF ADDITIONAL GENERATOR WEIGHT TO ENERGY CONSUMPTION OF THE TRAIN}

Specific energy consumption of a train depends on the total mass of the train and is given by:

$$
\begin{aligned}
& E_{s c p}=\left(0.01072 \cdot \frac{V_{m}^{2}}{\eta D} \cdot \frac{M_{e}}{M}+27.25 \frac{G}{\eta} \cdot \frac{D^{\prime}}{D}+\right. \\
& \left.0.2778 \frac{r}{\eta} \cdot \frac{D^{\prime}}{D}\right) W h / t-k m \text { (4) }
\end{aligned}
$$

Where Me is the dynamic mass of the train and $M$ is the dead weight of the train, $V_{m}$ is the maximum speed, $G$ is the gradient level, $\eta$ is the efficiency of gears, $\mathrm{r}$ is the train resistance per ton, $D^{\prime}$ is the distance over which energy is consumed and $\mathrm{D}$ is the total distance run including braking distance.

Since DC permanent magnet generators have small weight due to absence of stator winding, the effect of their additional weight is negligible compared to the weight of the train without them. Therefore, their effect on specific energy consumption is minimal. However, their effect has to be examined in details in the implementation of the project.

\section{RESULTS AND CONCLUSION}

Simulation of the system demonstrated that an amount of $300 \mathrm{~V}$ can be generated which is enough to supply the auxiliary system of the train. Here below is the output voltage from battery storage as displayed by scope 2 where the Y-Axis shows the generated voltage amplitude and X-Axis displays the discharge time up to $40 \%$ of the maximum voltage where batteries are recharged again. That is shown by the blue line on Figure 10 with the signal statistics shown in Fig 11.

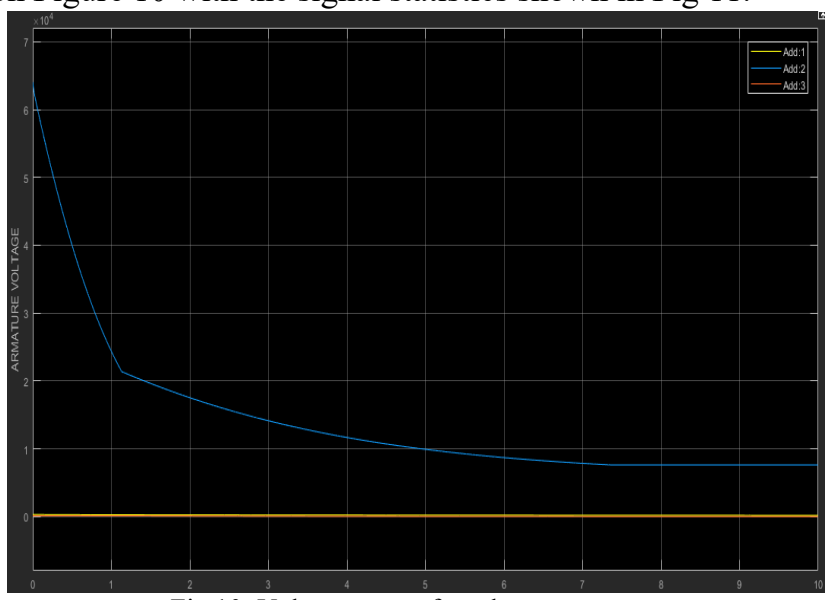

Fig 10: Voltage output from battery storage

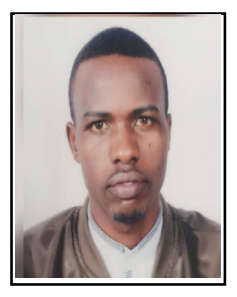

Jean d'amour Nizeyimana received a BSc degree in Electrical and Electronics Engineering from University of Rwanda, College of Science and Technology, in 2015, an MSc in Railway Engineering (Traction and Train Control) from the Addis Ababa University, Ethiopia, in 2019. He has worked as Electrical engineer in Rwanda, as Intern at Ministry of Infrastructure and as a he carried out academic internship at Bralirwa Industries Ltd, Addis Ababa Light Rail Transit(AALRT). email: jnizeyimana19@gmail.com

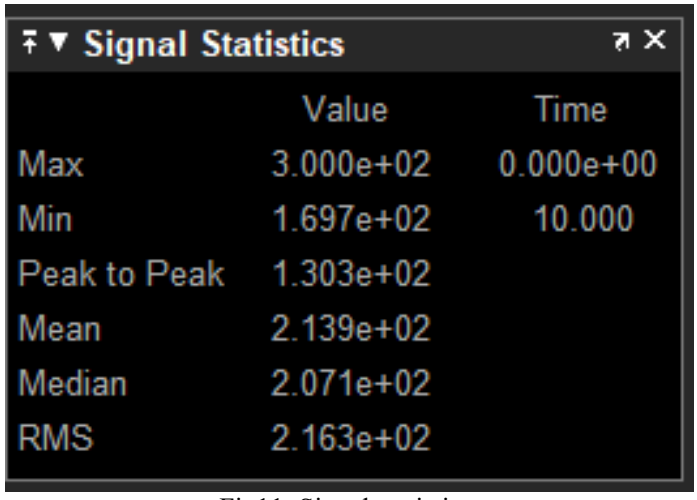

Fig11: Signal statistics

The simulation of the system demonstrated that electricity produced is enough to power the auxiliary system. The project can be implemented in electric trains, which will reduce the total energy consumption in the auxiliary system of the train. However, the designed system can be improved to generate much more voltage which can even be used to run the whole train system when there is power shortage from catenaries or third rail feeding system. Electricity generation by using this method which would pose a drag to the train as the magnetic energy needs to be countered resulting in using more energy for the locomotion to pull the train, magnetic bearings on the rotor shall be used which supports moving parts without physical contact ( generator and wheel axle) as they are able to levitate a rotating shaft(wheel axle) and permit relative motion with very low friction hence minimize energy used to pull the train and this will be done in the future research as well.

\section{REFERENCES}

[1] K. Jäger, O. Isabella, A. H. M. Smets, R. A. C. M. M. van Swaaij, and M. Zeman, SolarEnergy: Fundamentals, Technology, and Systems. 2014.

[2] B. . Theraja And A.K.Theraja, A Textbook Of Electrical Technology, Vol. I, No. I. Ram Nagar, New Delhi: S.Chand, 2005.

[3] K. Daware, "Permanent Magnet Dc (Pmdc) Motors," Electrical Easy. [Online].Https://Www.Electricaleasy.Com/2014/12/PermanentMagnet-Dc-Pmdc-Motors.Html. [Accessed: 31-May-2019].

[4] "Permanent Magnet DC Motor Repair." [Online]. Available: http://www.tigertek.com/permanent-magnet-motor-repair.html. [Accessed: 30-May-2019].

[5] H.-S. Han and D.-S. Kim, Magnetic Levitation: Maglev Technology and Applications. New York: Springer,2016.

[6] "Lithium Ion Battery Advantages \& Disadvantages," Electronicsnotes.[Online].Available:https://www.electronicsnotes.co $\mathrm{m} /$ articles/electronic_components/battery-technology/li-ion-lithiumion-advantages-disadvantages.php. [Accessed: 30-May-2019].

[7] A. Al-Haj Hussein and I. Batarseh, "A review of charging algorithms for nickel and lithium battery chargers," IEEE Trans. Veh. Technol., vol. 60 , no. 3 , pp. $830-838,2011$. 